\title{
Treatment of Heart Failure with Normal Ejection Fraction
}

\author{
Evandro Tinoco Mesquita and Antonio José Lagoeiro Jorge \\ Universidade Federal Fluminense (UFF), Niterói, RJ - Brazil
}

\begin{abstract}
Different from heart failure with reduced ejection fraction (HFREF), for which large studies have demonstrated the effectiveness of drug treatment to improve morbidity and mortality, no treatment study has shown definitive results in patients with heart failure with normal ejection fraction (HFNEF). HFNEF is more prevalent in women and the elderly and it is associated with multiple comorbidities. Although the optimum treatment has yet to be defined, the control of arterial hypertension and decreased fluid overload are important measures to control the syndrome.
\end{abstract}

In Brazil, the recommendations for the treatment of HF are based on the Review of the II Directives of the Brazilian Society of Cardiology for the diagnosis and treatment of Heart Failure - 2002. However, none of the recommendations is specific for patients with HFNEF, as they are based on general measures proposed by specialists.

This review aims at demonstrating the scientific evidence from recent clinical trials in HFNEF and future perspectives in terms of new medications.

\section{Introduction}

In the last years, it has been increasingly observed that many patients presenting heart failure (HF) have a normal left ventricular ejection fraction (LVEF), with a prevalence between $13 \%$ and $74 \%$, depending on the diagnostic criterion and the population profile ${ }^{1}$. The tendency towards an increase in this prevalence in the next years will be due to the aging of the population, mainly among women with comorbidities such as arterial hypertension, obesity, diabetes and atrial fibrillation².

Studies ${ }^{3,4}$ have shown that the occurrence of clinical events markedly increases after the first hospitalization due to HF and that one-third of the patients with HF can be rehospitalized within a one-year period ${ }^{5}$. Owan et $\mathrm{al}^{4}$ showed that the mortality one year after the first hospitalization due to heart failure with normal ejection fraction (HFNEF) would be $29 \%$ and due to heart failure with reduced ejection fraction

\section{Key words}

Heart failure/therapy; ventricular function, left; hypertrophy, left ventricular.

\footnotetext{
Mailing address: Evandro Tinoco Mesquita •

Rua General Polidoro, 192 - Botafogo - 22280-000 - Rio de Janeiro - RJ Brazil

E-mail: etmesquita@gmail.com

Manuscript received on August 06,2008; revised manuscript received on October $3^{\text {rd, }} 2008$; accepted on October 7, 2008.
}

(HFREF), 32\%; after five years, the mortality of patients with HFNEF and HFREF would be, respectively, $65 \%$ and $68 \%{ }^{4}$. The same study observed that, although the survival rate was higher in patients with HRNEF, the ones with HFREF had an increased probability of survival during the study period ${ }^{4}$. This fact is due to the development, throughout the years, of an effective, scientific-evidence based treatment from clinical trials for HFREF (Chart 1).

The prognosis of HFNEF, as well as of HFREF, is a poor one. In hospitalized patients, the mortality is similar in both groups and any observed difference favoring the patients with HFNEF becomes negligible after three months of hospital release ${ }^{6}$.

The mortality in HFNEF remains high because the causes of death are yet to be fully defined and there is a gap in the knowledge of the specific cause of death in HFNEF, which has started to be understood based on the last studies.

A study ${ }^{7}$ observed that individuals with HF presented high mortality, regardless of being classified as HFNEF or HFREF; however, patients with HFNEF presented a lower prevalence cardiovascular comorbidities and death in individuals with HFNEF is associated with pulmonary causes and neoplasias (Figure 1$)^{7}$. These findings emphasize the heterogeneity of $\mathrm{HF}$ and have implications in the design and interpretation of intervention studies to reduce mortality, mainly in HFNEF?. Additionally, it has been observed that, at the moment of hospital discharge, patients with HFREF received a more intense treatment than patients with HFNEF. Therefore, more aggressive therapeutic strategies might have, in the future, a significant impact on the outcome of $\mathrm{HFNEF}^{3}$.

There is a current need to develop an effective treatment based on large clinical trials for patients with HFNEF. The objective of the present review is to present the therapeutic developments for the treatment of HFNEF in the context of outpatient practice.

\section{Identifying the therapeutic targets in HFNEF}

To develop an effective treatment for HFNEF, it is necessary to understand its physiopathology, of which knowledge in the last years has been reviewed comprehensively through invasive studies and cardio-imaging techniques ${ }^{8}$.

The diastolic function abnormalities present in HFNEF consist in alterations in left ventricular (LV) relaxation and/or increase of its rigidity, which result in abnormalities in ventricular filling and increased filling pressure. Other conditions such as increased vascular rigidity, atrial dysfunction, neurohumoral activation and loss of chronotropic reserve during exercise can also contribute to the development of HFNEF². As in HFREF, evidence has shown that the activation of the aldosterone renin-angiotensin system (ARAS) has an important role in the 


\section{HEART FAILURE TREATMENT STUDIES}

\begin{tabular}{|c|c|c|c|}
\hline \multicolumn{4}{|l|}{ HFREF } \\
\hline$\overline{1 . A C E I}$ & 2. ARB & 3. ARA & 4. Digitalis DIG \\
\hline CONSENSUS-1 & ELITE & RALES & \\
\hline SOLVD & ELITE 2 & EPHESUS & \\
\hline V-HeFT II & CHARM & & \\
\hline OVERTURE & CRARM & & \\
\hline
\end{tabular}

$\begin{array}{llll}\text { 5. Beta-blockers } & & \text { 6. CRT } & \text { 7. Desfibrillator } \\ \text { PRECISE } & \text { CIBIS } & \text { COMPANION } & \text { SCD-HeFT } \\ \text { COPERNICUS } & \text { CIBIS II } & \text { CARE HF } & \\ \text { COMET } & \text { SENIORS } & & \\ \text { MDC/MERIT-HF } & \text { BEST } & & \end{array}$

\section{Statins \\ CORONA}

\section{HRNEF \\ 1. ACEI \\ PeP-CHF}

5. Beta-blockers SENIORS

\section{ARB I-Preserve} CHARM reserved

3. Digitalis

DIG Ancillary

4. ARA

Top Cat

Chart 1 - List of the main treatment studies for HFREF and HFNEF; HFREF - Heart Failure with Reduced Ejection Fraction; HFNEF - Heart Failure with Normal Ejection Fraction; ACEI - angiotensin-converting enzyme inhibitors; ARB - angiotensin-receptor blocker; CRT - cardiac resynchronization therapy; ARA - aldosterone receptor antagonist.

development of HFNEF, mainly through the trophic effects of angiotensin II on the vessels and myocardium, leading to hypertrophy and fibrosis, which worsens the relaxation and results in increased diastolic pressure of the LV (Figure 2$)^{2}$.

There are structural and functional differences between HFNEF and HFREF (Table 1). Regarding the morphology of the $L V$, the main one is the increased ventricular volume and the change in its shape due to the process of remodeling, which is more accentuated in patients with HFREF than in those with HFNEF9.

Patients with HFNEF can present significant systolic dysfunction with normal LVEF when assessed through the shortening of the longitudinal axis, which can be identified by tissue Doppler echocardiography (TDE). The preservation of the LVEF is directly related to the presence of hypertrophy in the $\mathrm{LV}(\mathrm{LVH})^{10}$.

Therefore, alterations in the cardiac relaxation, the presence of myocardial hypertrophy and remodeling are key abnormalities that alter the ventricular rigidity and the filling pressures, leading to exercise intolerance, which would be the first symptom of HFNEF and a determinant factor in the decrease of quality of life ${ }^{11}$.
Table 1 - Structural and functional comparison between HFNEF and HFREF

\begin{tabular}{lcc}
\hline & HFNEF & HFREF \\
\hline Diastolic dysfunction & +++ & +++ \\
\hline Systolic dysfunction & + & +++ \\
\hline Remodeling & $-/+$ & +++ \\
\hline LV Hypertrophy & concentric & eccentric \\
\hline Vascular Stiffness & +++ & ++ \\
\hline Decompensation & acute & Chronic/subacute \\
\hline
\end{tabular}

HFNEF - Heart Failure with Normal Ejection Fraction; HFREF - Heart Failure with Reduced Ejection Fraction; LV - left ventricle; Adapted from Willian C. Little Heart Failure with a normal left ventricular ejection fraction: Diastolic heart Failure; Transactions of the American Clinical and Climatological Association, vol. 119, 2008.

The TDE and the type B natriuretic peptide (BNP) are important diagnostic tools to assess patients with HFNEF, with the LVEF and the LV-end diastolic volume (EDV) helping to differentiate HFREF and high-output HF from HFNEF ${ }^{12}$. The HFNEF presents alterations in the diastolic and systolic 


\section{Review Article}

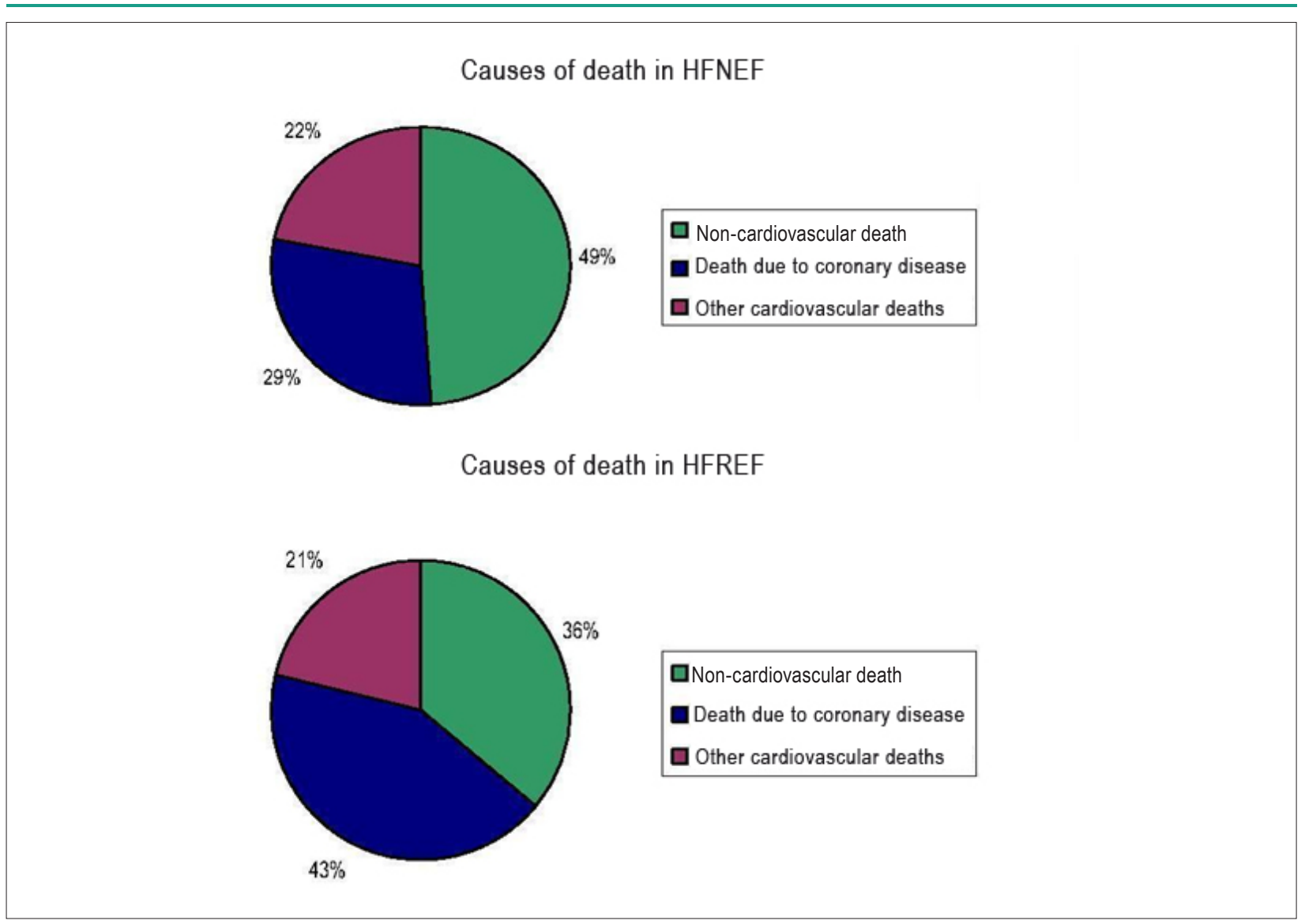

Figure 1 - Causes of death in Heart Failure - comparison between HFNEF and HFREF. Higher incidence of cardiovascular death in patients with HFREF than in those with HFNEF. Adapted from Danielle Henkel et al; Death in Heart Failure: A Community Perspective; Circulation: Heart Failure; 2008.

functions that are better assessed by the TDE than by the standard echo-Doppler (analysis of the transmitral flow). The assessment of the regional function through the measurement of longitudinal axis $\left(\mathrm{S}^{\prime}\right)$ and $\mathrm{E} / \mathrm{E}^{\prime}$ ratio for the assessment of the diastolic function are important measurements that can only be obtained through the $\mathrm{TDE}^{8}$.

\section{How to make the diagnosis}

The patient with HFNEF often does not present signs of systemic or pulmonary congestion, except for the acute pictures of decompensation. Thus, at the outpatient clinic, the most common complaint is dyspnea ${ }^{13}$.

The Directive of the European Society of Cardiology ${ }^{13}$ published in 2007 proposed new diagnostic criteria for HFNEF (Figure 3) focused on the parameters obtained through the $\mathrm{TDE}$, with special emphasis on the $\mathrm{E} / \mathrm{E}^{\prime}$ ratio, where $\mathrm{E}$ is the initial peak of the mitral flow and $E^{\prime}$ is the velocity of the mitral annulus obtained through the TDE. The $E^{\prime}$ measurement can be considered as non-invasive substitute of ventricular relaxation. The $\mathrm{E} / \mathrm{E}^{\prime}$ ratio overcomes the influence of the LV relaxation in the measurement of $E$ peak, and thus, reflects the pressure of the left atrium ${ }^{14}$.

The European directive establishes that an $E / E^{\prime}$ ratio $>$ 15 (which correlates with the LV-end diastolic pressure >
$18 \mathrm{mmHg}$ ), in the presence of LVEF $\geq 50 \%$ in non-dilated ventricles (end-diastolic volume index $<97 \mathrm{ml} / \mathrm{m}^{2}$ ), in patients with symptoms or signs of HF is diagnostic of HFNEF ${ }^{13}$. However, if the ratio is between 8 and 15, it can suggest a diastolic dysfunction, but other echocardiographic parameters should also be used to support this diagnosis. These include measurements of the LV mass index (> $122 \mathrm{~g} / \mathrm{m}^{2}$ in women and $>149 \mathrm{~g} / \mathrm{m}^{2}$ in men), left atrial volume index (LAV-I $>$ $40 \mathrm{ml} / \mathrm{m}^{2}$ ), transmitral flow Doppler ( E/A ratio $<0.5$ and time of $\mathrm{E}$ deceleration $>280 \mathrm{~ms}$ ) and pulmonary venous flow Doppler (Ard-Ad > 30ms). The directive also allows the identification of HFNEF without the parameters of TDE, using the electrocardiogram (ECG - presence of atrial fibrillation) and BNP-Pro-BNP measurements ${ }^{13}$.

\section{Treatment}

The objectives of the treatment of HFNEF are similar to those of HFREF, aiming at improving the quality of life with symptom improvement, increasing exercise tolerance and reducing the number of hospitalizations, increasing survival (Table 2).

The most recent directives of the Brazilian Society of Cardiology $(2002)^{15}$, European Society $(2008)^{16}$ and ACC/AHA (2005) ${ }^{17}$ for the diagnosis and treatment of HF mention the HFNEF. However, the recommendations for the 


\section{HFNEF - PHYSIOPATHOLOGICAL ASPECTS}

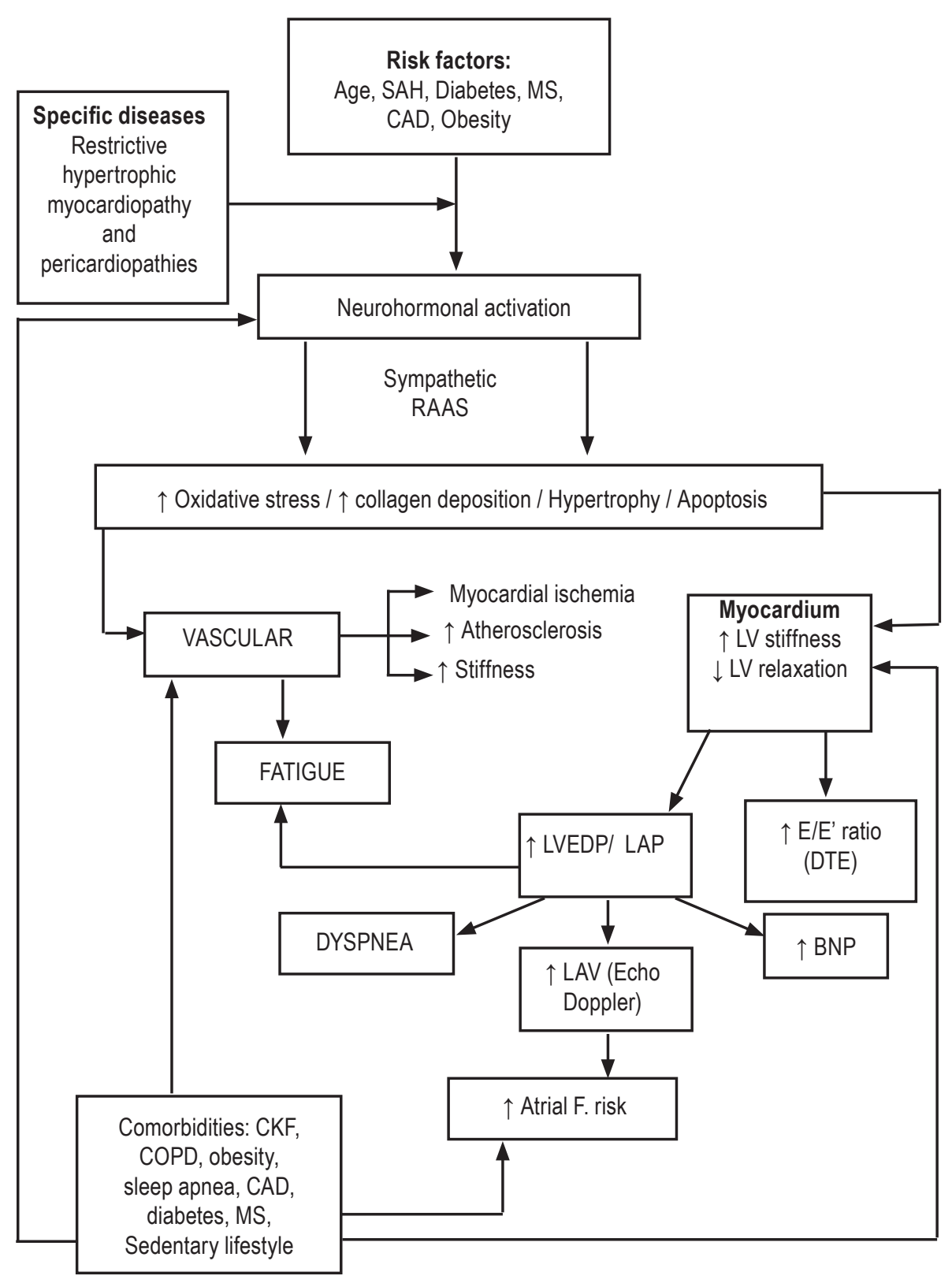

Figure 2 - Physiopathological Aspects; HFNEF - Heart Failure with Normal Ejection Fraction; CAD - Coronary Atherosclerotic Disease; RAAS - renin-angiotensinaldosterone system; LV - left ventricle; EDP - end-diastolic pressure; LAP - left atrium pressure; E/E' ratio; $E$ - transmitral flow velocity in early diastole; $E^{\prime}$ - myocardial velocity in early diastole; LAV - left atrium volume; BNP - type B natriuretic peptide; Atrial F-Atrial fibrillation; CKF - chronic kidney failure; COPD - chronic obstructive pulmonary disease; CKF - chronic kidney failure; MS - Metabolic Syndrome.

treatment are speculative, due to the limited data available. In the European Directive of 2008, the recommendation is to use a therapeutic approach similar to that used for HFREF. The directive of the ACC/AHA recommends the management of HFNEF with class IIb with a level of evidence C. The directives of the Brazilian Society of Cardiology, also due to the lack of consistent data, recommend the same medications used in the management of HFREF, with class Ila and recommendation grade $\mathrm{B}$.
The choice of medication in HFNEF, according to the directive of the ACC/AHA is based on evidence for four key points:

1) Control of systolic and diastolic hypertension;

2) Control of ventricular response in patients with atrial fibrillation;

3) Control of pulmonary congestion and peripheral edema with diuretics;

4) Coronary revascularization in patients with $C A D$ in whom 


\section{Review Article}

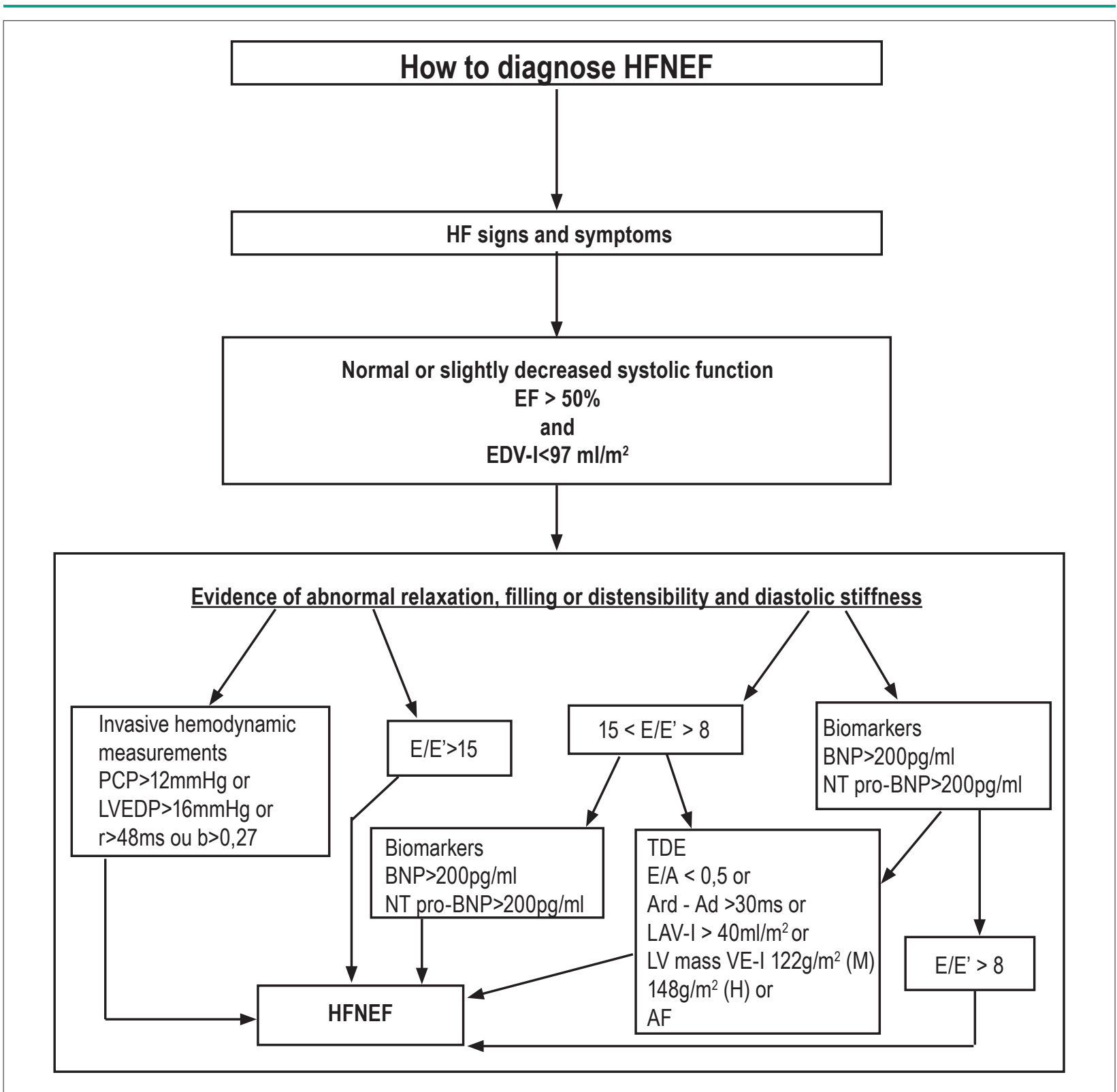

Figure 3 - How to diagnose HFNEF: Flow chart; HF - heart failure; EF - ejection fraction; EDV - end-diastolic volume; PCP - pulmonary capillary pressure mean; $r$ - time constant of left ventricular (LV) relaxation; b-Left Ventricular Chamber Stiffness Constant; EDP - end-diastolic pressure; LV - left ventricle; TDE - tissue Doppler echocardiography; AF-atrial fibrillation; $F$ - female / M - male; HFNEF - Heart Failure with Normal Ejection Fraction; $E$-transmitral flow in early diastole; $E^{\prime}$ - stretch velocity in early diastole; BNP - type B natriuretic peptide; E/A - ratio of $E$ to mitral peak velocity of late filling (A); DT - deceleration time; LAV-I - left atrium volume; Ard - duration of the reverse flow of atrial systole to pulmonary vein; $A d$ - duration of atrial flow through the mitral valve; HFREF - heart failure with reduced ejection fraction.

ischemia has an adverse effect on the diastolic function.

The decrease in the LVH is an important therapeutic goal in HFNEF, as it can lead to an improvement in the diastolic function. A meta-analysis published in 2003 evaluated the efficacy of different medications in the reversal of LVH in patients with hypertension. Eighty studies were assessed for the relative decrease in LV mass index (Figure 4$)^{18}$.

The treatment of HFNEF is still empirical and the recommendations are based on the outcomes of small clinical trials, personal experience and the control of comorbidities that correlate with HFNEF (Figure 5).

Except for the CHARM-preserved ${ }^{19}$, SENIORS, PEP-CHF and DIG studies ${ }^{20}$, no large-scale study - randomized, double-blind, placebo-controlled - is available for the treatment of patients with $\mathrm{HFNEF}^{21}$.

\section{Non-pharmaceutical approach}

The first great challenge is how to conduct a change in the lifestyle, particularly in elderly individuals with HFNEF, as few patients will adhere to a program of new life styles 
Table 2 - HFNEF management measures

\begin{tabular}{|c|c|c|}
\hline AlMS & Measures & Medications / daily dose \\
\hline Reduce congestion & $\begin{array}{l}\text { Salt restriction } \\
\text { diuretics } \\
\text { ACE Inhibitors } \\
\text { ARB }\end{array}$ & $\begin{array}{c}<2 \mathrm{~g} \text { table salt/day, } \\
\text { furosemide } 10-120 \mathrm{mg} \\
\text { Hidroclorotiazida } 12.5-25 \mathrm{mg} \\
\text { Enalapril } 2.5-40 \mathrm{mg} \\
\text { Captopril } 37.5 \mathrm{mg} \text { a } 150 \mathrm{mg} \\
\text { Losartan } 25-100 \mathrm{mg} \\
\text { Candesartan } 4-32 \mathrm{mg}\end{array}$ \\
\hline Control hypertension & Decrease $\mathrm{BP}<130 \times 80 \mathrm{mmHg}$ & $\begin{array}{l}\text { Clortalidone } 12.5-25 \mathrm{mg} \\
\text { Hidroclorotiazida } 12.5-25 \mathrm{mg} \\
\text { Bisoprolol } 1.25-10 \mathrm{mg} \\
\text { Amlodipine } 2.5-10 \mathrm{mg} \\
\text { Enalapril } 2.5-40 \mathrm{mg} \\
\text { Candesartan } 4-32 \mathrm{mg} \\
\text { Losartan } 50-100 \mathrm{mg} \\
\text { Valsartan } 80-320 \mathrm{mg} \\
\text { Ibesartan } 150-300 \mathrm{mg}\end{array}$ \\
\hline Regression of LVH. prevent myocardial fibrosis & $\begin{array}{l}\text { ACE Inhibitors } \\
\text { ARB } \\
\text { ARA }\end{array}$ & $\begin{array}{c}\text { Enalapril } 2.5 \text { - } 40 \mathrm{mg} \\
\text { Captopril } 37.5 \mathrm{mg} \text { a } 150 \mathrm{mg} \\
\text { Ramipril } 5 \text { - } 20 \mathrm{mg} \\
\text { Losartan } 25-100 \mathrm{mg} \\
\text { Candesartan } 4-32 \mathrm{mg} \\
\text { Spironolactone } 25-75 \mathrm{mg}\end{array}$ \\
\hline Treat and prevent myocardial ischemia & $\begin{array}{l}\text { Nitrates } \\
\text { Beta-blockers } \\
\text { CCB } \\
\text { Invasive Procedures }\end{array}$ & $\begin{array}{l}\text { Isosorbide Dinitrate } 30-180 \mathrm{mg} \\
\text { Isosorbide Mononitrate } 30-90 \mathrm{mg} \\
\text { Metoprolol } 12.5-200 \mathrm{mg} \\
\text { Bisoprolol } 1.25-10 \mathrm{mg} \\
\text { Carvedilol } 6.25-50 \mathrm{mg} \\
\text { Diltiazem } 120-540 \mathrm{mg} \\
\text { Verapamil } 120-360 \mathrm{mg} \\
\text { Percutaneous angioplasty } \\
\text { Revascularization surgery }\end{array}$ \\
\hline
\end{tabular}

ACE - angiotensin-converting enzyme; ARB - angiotensin receptor blocker; LVH - left ventricular hypertrophy; ARA - aldosterone receptor antagonist; CCB - calcium-channel blocker; Adapted from Michael R Zile; Treatment and Prognosis of Diastolic Heart Failure; Up-to-date; review 31/01/2008.

in substitution of models that have been used for decades. Stop smoking is a fundamental behavior change in the treatment of HFNEF 22 .

Alcohol has a deleterious effect on the heart and increases blood pressure and must be avoided by patients with HFNEF. Regular physical activity decreases blood pressure (BP) and improves endothelial function; thus, functional class II patients should be encouraged to perform some type of physical activity daily ${ }^{22}$. Weight reduction also reduces blood pressure and has an important role in diabetic patients. The reduction in table salt consumption is also effective in the control of $\mathrm{BP}^{23}$. The preservation of kidney function is important in patients with HFNEF and prophylactic measures to prevent the deterioration of the renal filtration capacity must always be adopted.

Other associated comorbidities that directly or indirectly worsen the diastolic function, such as anemia, hypothyroidism, obesity and sleep apnea must be investigated and treated adequately ${ }^{23}$.

\section{Calcium-channel blockers}

Calcium-channel blockers (CCB), which decrease the heart rate $(\mathrm{HR})$ and the myocardial contractility, can be beneficial for patients with HFNEF ${ }^{24}$.

Two small studies have compared a placebo with verapamil25,26. Setaro et $\mathrm{al}^{25}$ studied 22 patients with HF and LVEF > 45\% and observed that verapamil improved symptoms and exercise tolerance when compared to the placebo $^{22}$. The results by Hung et al, who studied 15 patients, were very similar, with symptom and exercise tolerance improvement ${ }^{26}$.

\section{Beta-blockers}

In the normal heart, when there is an increase in the HR, the response will be an increase in contractility and relaxation velocity. In HFNEF, due to the slow decline in the LV pressure, there is an increase in the end-diastolic pressure (EDP). In patients with diastolic dysfunction grades I and II, the duration of diastole is 


\section{Review Article}

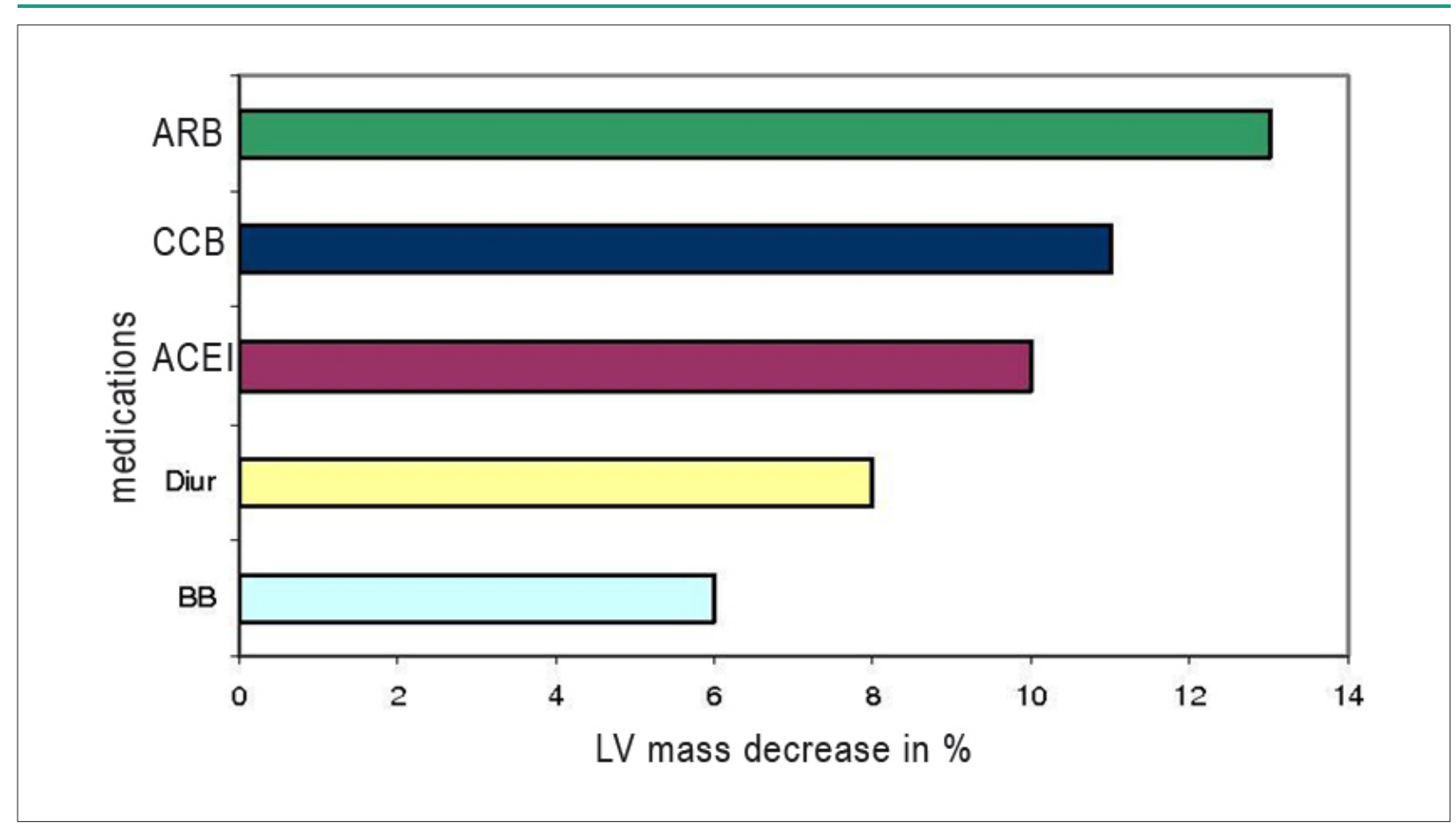

Figure 4 - Effect of therapy with each of the five anti-hypertensive medications on the LV hypertrophy regression (Klingbeil. AU. Schneider M. et al. Am J Méd;2003(115);4146; ARB - angiotensin receptor blocker; CCB - calcium-channel blocker; ACEI - angiotensin-converting enzyme inhibitor; Diur - Diuretics; BB - beta-blocker.

fundamental and beta-blockers (BB) improve the symptoms, as by reducing the HR, they increase the time of relaxation duration, and then a higher diastolic filling occurs. Differently, in patients with grades III and IV of diastolic dysfunction, the ventricular filling is complete in the middle of diastole and these patients have a fixed systolic volume. The decrease in the HR between 50 and 60 bpm can further reduce the cardiac output (CO), worsening the symptoms of these patients. The treatment with beta-blockers must be initiated with low doses, which should be increased gradually until reaching the maximum recommended dose ${ }^{27}$.

Aronow et $\mathrm{al}^{28}$ studied 158 patients with HF and LVEF $>40 \%$ post-acute myocardial infarction (AMI); one group received propranolol and the other did not. After one year of treatment, an improvement in the LVEF, a higher reduction in the LV mass and a lower mortality (56\% vs. $76 \%$ ) were observed in the group receiving propranolol, when compared to the group that did not use the drug ${ }^{28}$.

The study has methodological limitations due to the lack of a placebo group and also due to the fact that it selected a group of ischemic patients, as the beneficial action of betablockers in patients with $\mathrm{AMI}$ is well-recognized.

Dobre et al ${ }^{29}$ observed 443 patients with HF and LVEF $>40 \%$, hospitalized due to decompensated $\mathrm{HF}$, of which $227(51 \%)$ received $\mathrm{BB}$ at the hospital discharge. The patients were followed for 25 months. The results showed that the mortality due to all causes was $17.6 \%$ in the group that received $\mathrm{BB}$ and $33.8 \%$ in the group that did not. In spite of its limitations (non-randomized study), this prospective observational study was the first to suggest that the prescription of a BB is associated with reduced mortality in patients with advanced HFNEF ${ }^{29}$.
The SENIORS study ${ }^{30}$, which involved 2,000 patients randomized to placebo and nebivolol, was the first study to evaluate the effects of nebivolol in elderly patients with $\mathrm{HF}$, of which $35 \%$ presented preserved LVEF $^{30}$. Nebivolol decreased the combined primary outcome of death or hospitalization, but the effect on all causes of mortality was lower when compared with younger patients with systolic dysfunction. The study was not designed to evaluate separately the effects of nebivolol in patients with HFNEF ${ }^{30}$.

The Swedic ${ }^{31}$ study assessed 113 patients with symptoms of HFNEF, who were randomized to treatment with carvedilol or placebo, with assessment performed by echocardiogram at the initial assessment and 6 months later. Carvedilol use resulted in an improvement of the E/A ratio, but without a significant improvement in DT, time of isovolumetric relaxation or pulmonary vein flow velocity ${ }^{31}$.

The main benefits of BB in HFNEF are associated with the increase in diastolic filling, improving the myocardial perfusion and thus, reducing the ischemia, in addition to promoting an anti-hypertensive effect, decreasing LV hypertrophy and reducing cardiac arrhythmias ${ }^{29}$.

\section{Diuretics}

Diuretics improve the HFNEF symptoms, as they reduce the intravascular volume and lead the LV to a better position in the end-diastolic pressure-volume curve ${ }^{27}$.

Therapies that result simply in a change of position in the end-diastolic pressure-volume curve, without changing the shape of the curve, are probably analog to the treatment of fever with paracetamol, i.e., they improve the symptoms, but they do not 


\section{Treatment algorithm - HFNEF}

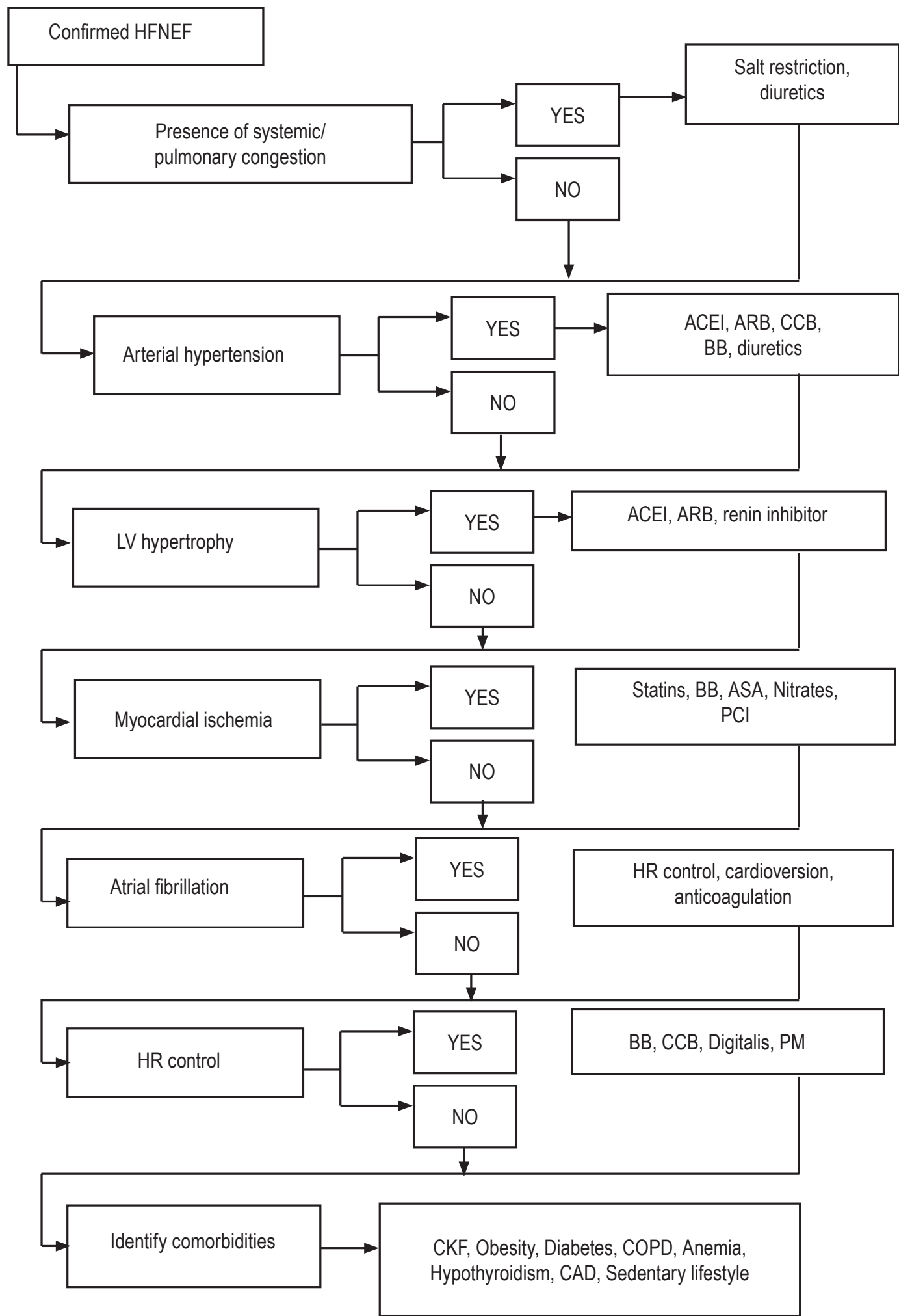

Figure 5 - Treatment algorithm; HFNEF - heart failure with normal ejection fraction; ACEI - angiotensin-converting enzyme inhibitor; ARB - angiotensin receptor blocker; CCB - calcium-channel blocker; BB - beta-blocker; $A S A$ - acetylsalicylic acid; HR - heart rate; CKF - chronic kidney failure; COPD - chronic obstructive pulmonary disease; $\mathrm{PCl}$ - percutaneous coronary intervention; $\mathrm{PM}$ - pacemaker; 


\section{Review Article}

influence the cause and therefore, have no impact on long-term survival ${ }^{27}$.

The Hong-Kong study ${ }^{32}$, interrupted early due to recruiting difficulties, showed that the diuretic therapy improves the symptoms of HFNEF and that neither irbesartan nor ramipril had an additional effect to the use of diuretics ${ }^{32}$

Patients with moderate HFNEF and arterial hypertension must use low doses of Thiazide diuretics, as the efficacy of low doses of diuretics as the first-choice treatment for the prevention of cardiovascular events has been well documented ${ }^{33}$.

Patients that present severe HFNEF might need a loop diuretic to control pulmonary congestion. The basis for this treatment resides in a higher effectiveness of the loop diuretics, mainly if the kidney function is affected ${ }^{34}$.

\section{Angiotensin-converting enzyme inhibitor}

Neurohormonal modulators are drugs that influence arterial hypertension, coronary artery disease, atrial fibrillation and diabetes mellitus.

These medications are the basis of the treatment of HFNEF, as they are effective for the control of these diseases that contribute to the worsening of the diastolic function ${ }^{6}$.

The angiotensin II predisposes to the onset of LVH, reduces relaxation and increases ventricular rigidity ${ }^{24}$. Medications that modulate the neurohormonal system, in addition to presenting beneficial hemodynamic effects, also reduce the growth of smooth muscle cells, prevent collagen deposition, reduce growth factor expression and promote the regression of myocardial fibrosis ${ }^{27}$.

Studies have shown the decrease in LV mass with angiotensin-converting enzyme inhibitors (ACEI). Brilla et $\mathrm{al}^{35}$ described the regression of myocardial fibrosis by lisinopril in patients with hypertensive heart disease. The study assessed 35 patients with primary arterial hypertension, $\mathrm{LVH}$ and diastolic dysfunction. The patients were randomized to receive lisinopril or hydrochlorothiazide. The primary outcome was the assessment of myocardial fibrosis through an endomyocardial biopsy, with the measurement of the collagen volume fraction and myocardial concentration of hydroxyproline. In the lisinopril group, there was a mean decrease of $6.9 \%$ in the concentration of hydroxyproline and a mean decrease of 9.9 $\mathrm{ug} / \mathrm{mg}$ to $8.3 \mathrm{ug} / \mathrm{mg}$ of LV weight. The results were associated with an increase in the E/A ratio (0.72 to 0.91$)$ and a decrease in the time of isovolumetric relaxation $(123 \mathrm{~ms}$ to $81 \mathrm{~ms}$ ). The study concluded that, in patients with hypertensive cardiopathy, the lisinopril reduced the myocardial fibrosis, regardless of the $\mathrm{LVH}$ regression, which is followed by an improvement in the diastolic function ${ }^{35}$.

The PEP-CHF study ${ }^{36}$, which was a double-blind one, compared a placebo with perindopril $4 \mathrm{mg}$, in 850 patients (age $>70$ yrs) with HF and preserved EF. The combined primary outcome was mortality due to all causes and hospitalization after one year of follow-up. The effects of the perindopril on the morbimortality during one year were uncertain, as the study had little statistical power to evaluate primary outcomes. However, there was an improvement in symptoms and in the capacity to perform exercises in the perindopril group, as well as a lower number of hospitalizations during the first year of follow-up ${ }^{36}$.

\section{Angiotensin-receptor blockers}

The CHARM-Preserved ${ }^{19}$ study was designed to evaluate the role of angiotensin-receptor blockers (ARBs) in patients with HFNEF (LVEF > 40\%). The study evaluated 3,023 patients that were randomized to candesartan or placebo after 36.6 months of follow-up. The primary outcome of the study (cardiovascular death or hospitalization due to HF) occurred in $22 \%$ of the group receiving candesartan and in $24 \%$ of the placebo group. The study showed a similar mortality rate between the two groups, but the number of hospitalizations was lower in the candesartan group. Candesartan showed a moderate impact in the prevention of hospitalizations due to HF in patients with LVEF > 40\%; however, there was no difference regarding the mortality rate between the two groups ${ }^{19}$.

\section{Aldosterone receptor antagonists}

Aldosterone-receptor blockers, such as spironolactone and eplerone are potassium-saving diuretics capable of reducing the BP, improving endothelial function and inhibiting fibrosis. The difference between spironolactone and eplerone is that the latter has a reduced effect on progesterone and androgen receptors. Comparative studies have shown that eplerone has an anti-hypertensive effect similar to enalapril, amlodipine, losartan and spironolactone ${ }^{6}$. Spironolactone suppresses the vascular conversion of angiotensin II, improving the endothelial function and inhibiting perivascular fibrosis. The chronic treatment with spironolactone decreases the LV mass and markers of myocardial fibrosis in plasma ${ }^{6}$.

Eplerenone has similar effects to those of spironolactone. Studies such as the 4E-Left Ventricular Hypertrophy ${ }^{37}$ confirmed the beneficial effects of eplerenone in reducing the LV mass in patients with arterial hypertension. In this study, patients that received $200 \mathrm{mg}$ of eplerenone were compared with patients that received $40 \mathrm{mg}$ of enalapril and patients that received a combination of $200 \mathrm{mg}$ of eplerenone and $10 \mathrm{mg}$ of enalapril. The primary outcome was the alteration in LV mass in a 9-month period. Eplerenone was as effective as enalapril in reducing the $\mathrm{LVH}$ and in the control of BP. The combination of eplerenone and enalapril was more effective in reducing the LV mass and systolic pressure than eplerenone alone ${ }^{37}$.

The changes in LV mass and hypertrophy have important implications for the treatment of HFNEF. Although ACEI and ARBs reduce the levels of aldosterone in blood in the beginning of the treatment, there is a rebound effect after some time, in which the levels of aldosterone increase again in spite of the maintained treatment. Thus, medications that inhibit the action of aldosterone can have a differential role in the treatment of HFNEF'.

\section{Renin inhibitors}

The ARAS block can also be obtained through the inhibition of renin through aliskiren, a new renin inhibitor (RI), which is active by the oral route of administration. No studies have been carried out in patients with HFNEF, only concluded studies with patients that presented HFREF ${ }^{38}$. 
Digoxin

The digitalis is one of the oldest medications used in the control of HF, but it has been historically considered counterindicated in patients with HFNEF. ${ }^{2}$ Theoretical considerations suggest a potential benefit, as well as damage caused by digoxin in this group of patients. For instance, digoxin can improve the active energy dependence of the diastolic function $^{39}$, which can consequently lead to beneficial effects in the neurohormonal profile. On the contrary, digitalis can produce an increase in the systolic energy requirement, adding an overload of cytosolic calcium in the diastole. This effect might not be clinically apparent, but during a hemodynamic stress, the digitalis can promote or contribute to diastolic dysfunction ${ }^{2}$.

The DIG study ${ }^{20}$ was, until recently, the only large-scale study of a drug for patients with $\mathrm{HFNEF}^{24}$. As part of the entire DIG Program, a study was carried out with 988 patients with HF and LVEF $>45 \%$, who were randomized to receive placebo or digoxin. By comparison, 6,800 patients with HFREF were randomized to receive placebo or digoxin. In the HFNEF group, the percentage of death was the same as in the placebo group (23.4\%). The digoxin did not reduce mortality, but reduced the rate of hospitalization (risk rate of 0.82 for digoxin $)^{20}$.

In spite of the DIG study results, digoxin is not broadly used in the treatment of patients with HFNEF, as other agents can be more effective.

\section{Statins}

The use of statins has increased in the last decade, mainly due to the large number of clinical trials that demonstrated its effectiveness in several models of disease ${ }^{2}$.

In general, the benefit of statins in patients with HFNEF can be divided in two groups: First, statins are associated with the decrease in blood levels of lipids, which is associated with the decrease of cardiovascular events. Second, statins can have an effect that is independent from lipid level decrease (pleiotropic effect), which can include the decrease in the LV mass and cardiac fibrosis, a favorable effect in the neurohumoral system and an increase in the arterial elasticity, effects that can have an impact in the evolution of diastolic dysfunction ${ }^{2}$.

In a retrospective analysis of a small group of 137 patients with $\mathrm{HFNEF}^{37}$, the use of statins was associated with improved survival, with a relative risk of death of $0.22^{40}$.

\section{Trimetazidine}

Trimetazidine is a drug that modifies the use of energy substrates in the heart through the inhibition of cardiac fatty acid oxidation, thus improving myocardial ischemia. A study showed that the use of trimetazidine, with an optimized specific therapy in elderly patients with ischemic myocardiopathy, has beneficial effects on the systolic and diastolic function and improves quality of life $\mathrm{e}^{41}$.

\section{Future perspectives}

The ideal therapeutic agent should have as objective the mechanisms that cause the HFNEF. This agent should then improve calcium homeostasis, block the neurohormonal activation, prevent and reverse fibrosis and improve the ventricular and arterial elasticity. Some existing medications already have such properties and many others are being developed. Unfortunately, there have been few randomized, double-blind, placebo-controlled studies that evaluated the efficacy and safety of these measurements in the treatment of HFNEF. The difficulties that have prevented the performance of such studies - lack of acknowledgement of the importance of HFNEF, difficulty to define the profile of the population to be studied, lack of concordance in the definition of the diagnostic criteria for HFNEF - seem to have decreased in the last years, with the improvement of the knowledge on the physiopathology of HFNEF and also in relation to new diagnostic methods such as BNP and TDE.

The I-Preserve study ${ }^{42}$ is a large, randomized, doubleblind, placebo-controlled study, involving 4,128 patients that will investigate the benefits of irbesartan in HFNEF. The recruiting phase was completed in 2005 and the final results are predicted for the end of 2008. The inclusion criteria were: patients aged at least 60 years, symptoms of HF with LVEF $\geq 45 \%$ and hospitalization due to HF in the last six months or evidence of HF with diastolic dysfunction. The primary outcome is death due to all causes or hospitalization due to CVD. The main difference between the I-Preserve and the CHARM studies is in the cutoff for the LVEF $(40 \% \times 45 \%)^{42}$.

Another ongoing study (recruiting phase) is the TopCat study, which will evaluate the effects of spironolactone versus placebo in patients with HFNEF (LVEF $\geq 45 \%$ ). The primary outcome is a combination between cardiovascular mortality, aborted cardiac death or hospitalization due to HF. The study will be finished in July $2012^{2}$.

The increase in ventricular and vascular rigidity present in HFNEF is due, in part, to the formation of non-enzymatic cross-bridges that develop between advanced glycated end products (AGE) and proteins such as collagen and elastin. A thiazolium derivative known as alagebrium (ALT 711) seems to be efficient to break the cross-bridges and thus, improve the ventricular distensibility and increase arterial compliance. Initial clinical studies showed an increase in arterial compliance in elderly individuals with systolic arterial hypertension. Alagebrium can therefore be a beneficial agent in the treatment of HFNEF 22 .

Little et $\mathrm{al}^{43}$ evaluated alagebrium in an open study with 23 stable patients with HFNEF (LVEF $\geq 50 \%$ ) for 16 weeks. Alagebrium use was associated with decreased LV mass, improvement in diastolic dysfunction index at the TDE and improvement in the quality of life. However, there was no alteration in the BP, in pulse pressure and aortic distensibility. Other studies at phase II with the medication are currently being carried out (check www.clinicaltrials.gov) ${ }^{22}$.

One of the reasons why the use of beta-blockers has shown to be useful in the treatment of HF is due, in part, to the decrease in HR. As the HR is one of the main determinants of myocardial oxygen consumption, the decrease in HR can be related to an improvement in ischemia ${ }^{44}$. Ivabradin, a HR selective reduction agent that acts by blocking the type If potassium channel in the cells of the sinoatrial node, 


\section{Review Article}

demonstrated beneficial effects in the decrease of myocardial ischemia through a decrease in HR. Ivabradin might be useful for the treatment of patients with HFNEF, as there is a parallel between the decrease in HR and a clinical improvement in HF. The use of ivabradin can improve the clinical picture of HFNEF by prolonging the time of diastole through the HR decrease, without a negative impact on ventricular function ${ }^{45}$. There is an ongoing study with ivabradin in HF with LVEF < $40 \%$, the BEAUTIFUL Study, which will be an important step in determining the importance of HR in patients with CAD and ventricular dysfunction ${ }^{44}$.

Another ongoing study involves the drug MCC-135, which would be used to improve the diastolic function by increasing the absorption of calcium by the sarcoplasmatic reticulum and inhibiting the sodium-potassium exchange pump. The MCC135-GO1 is a double-blind, randomized, placebocontrolled study at phase II, carried out in 500 patients with HF, of which 230 have HFNEF. The results of the study have not been presented yet ${ }^{46}$.

Researchers have been very interested in the development of endothelin receptor antagonists for the treatment of HF. Nevertheless, the attempts to use bosentan, darusentan and tezosentan in patients with HFREF have been unsuccessful ${ }^{47}$. Currently, it has been acknowledged that endothelin might have an important role in the development of diastolic dysfunction. The endothelin interacts with the ARAS and metalloproteinases in the development of diastolic dysfunction and this process can be controlled by the type-A endothelin receptor antagonist.

The cardiac resynchronization therapy (CRT) for patients with HFREF with dyssynchrony has shown to improve both systolic and diastolic function ${ }^{48}$, and the diastolic indices seem to improve after the CRT, especially in patients with non-ischemic cardiomyopathy ${ }^{48}$.

The experience of CRT in patients with HFNEF is still limited and the significance of the dyssynchrony in patients with HFNEF is yet to be clarified.

\section{Conclusion}

We have observed, in the last years, an increase in the understanding of the physiopathological alterations involved in HFNEF, in which the importance of the diastolic function in relation to the mechanisms of ventricular filling, relaxation and elasticity, in addition to the ventricular/arterial rigidity and the left atrium function, have an important role in the physiopathology of HFNEF. The perfect understanding of these alterations will help future researches for new therapies for HFNEF.

The establishment of criteria for the diagnosis and ruling out of HFNEF is useful not only for the individual care of patients, but also for the recruiting in clinical trials that will evaluate therapies for HFNEF.

Ongoing studies, with medications currently employed in the treatment of HF and new drugs and technologies being developed, will modify the treatment of HFNEF in the next decades, allowing a better quality of life for patients with this severe disease.

\section{Potential Conflict of Interest}

Evandro Tinoco Mesquita is the national coordinator of IPreserve Study carried out by SANOFI-AVENTIS Laboratories and Bristol-Myers-Squibb.

\section{Sources of Funding}

There were no external funding sources for this study.

\section{Study Association}

This article is part of the thesis of master submitted by Antônio Jorge Lagoeiro Jorge, from Universidade Federal Fluminense.

\section{References}

1. Vasan RS, Benjamin EJ, Levy D. Prevalence, clinical features and prognosis of diastolic heart failure: an epidemiologic perspective. J Am Coll Cardiol. 1995; 26: 1565-4

2. Das A, Abraham S, Deswal A. Advances in the treatment of heart failure with a preserved ejection fraction. Curr Opin Cardiol. 2008; 23: 233-40.

3. Tribouilloy C, Rusinaru D, Mahjoub H, Souliere V, Lévy F, Peltier M, et al. Prognosis of heart failure with preserved ejection fraction a 5 year prospective population-based study. Eur Heart J. 2008; 29: 339-47.

4. Owan TE, Hodge DO, Herges RM, Jacobsen SJ, Roger VL, Redfield MM. Trends in prevalence and outcome of heart failure with preserved ejection fraction. N Engl J Med. 2006; 355: 251-9.

5. Hogg K, Swedberg K, McMurray JJV. Heart failure with preserved left ventricular systolic function: epidemiology, clinical characteristics, and prognosis. J. Am. Coll Cardiol. 2004; 43: 317-27.

6. RappJA, Gheorghiade M. Role of neurohormonal modulators in heart failure with relatively preserved systolic function. Cardiol Clin. 2008; 26: 23-40.

7. Henkel D, Redfield MM, Weston S, Gerber Y, Roger V. Death in heart failure:

a community perspective. Circ Heart Fail. 2008; 1: 91-7.

8. Kasner M, Westermann D, Steendijk P, Gaub R, Wilkenshoff U, Weitmann K, et al. Utility of Doppler echocardiography and tissue Doppler imaging in the estimation of diastolic function in heart failure with normal ejection fraction: a comparative Doppler-conductance catheterization Study. Circulation. 2007; 116: 637-47.

9. Mann DL, Bristow MR. Mechanisms and models in heart failure: the biomechanical model and beyond. Circulation. 2005; 111: 2837-49.

10. Maclver DH, Townsend M. A novel mechanism of heart failure with normal ejection fraction. Heart. 2008, 94: 446-9.

11. Westermann D, Kasner M, Steendijk P, Spillmann F, Riad A, Weitmann K, et al. Role of left ventricular stiffness in heart failure with normal ejection fraction. Circulation. 2008; 117: 2051-60.

12. Sanderson JE. Heart failure with a normal ejection fraction. Heart. 2007; 93 : 155-8.

13. Paulus WJ, Tschöpe D, Sanderson JE, Rusconi C, Flachskampf FA, Rademakers $\mathrm{FE}$, et al. How to diagnose diastolic heart failure: a consensus statement on 
the diagnosis of heart failure with normal left ventricular ejection fraction by the Heart Failure and Echocardiography Associations of the European Society of Cardiology. Eur Heart J. 2007; 28: 2539-50.

14. Arques S, Roux E, Luccioni R. Current clinical applications of spectral tissue Doppler echocardiography ( $E / E^{\prime}$ ratio) as a noninvasive surrogate for left ventricular diastolic pressures in the diagnosis of heart failure with preserved left ventricular systolic function. Cardiovasc Ultrasound. 2007; 5: 5-16.

15. Sociedade Brasileira de Cardiologia. Revisão das II Diretrizes para o diagnóstico e tratamento da insuficiência cardíaca: grupo de estudos de insuficiência cardíaca (GEIC). Arq Bras Cardiol. 2002; 79 (supl. 4): 1-30.

16. Dickstein K, Cohen-Solal A, Filippatos G, McMurray JJV, Ponikowski P, PooleWilson PA, et al. ESC Guidelines for the diagnosis and treatment of acute and chronic heart failure 2008: The Task Force for Diagnosis and Treatment of Acute and Chronic Heart Failure 2008 of European Society of Cardiology. Eur J Heart Fail. 2008; 29: 2388-442.

17. Hunt SA, Abraham WT, Chin MH, Feldman AM, Ganiats TG, Jessup M, et al. ACC/AHA 2005 Guideline Update for the Diagnosis and Management of Chronic Heart Failure in the Adult: a report of the ACC/AHA Task Force on Practice Guidelines: developed in collaboration with the American College of Chest Physicians and The International Society for Heart and Lung Transplantation: endorsed by the Heart Rhythm Society. Summary article. Circulation. 2005; 112: 1825-52.

18. Klingbeil AU, Schneider M, Martus P, Messerli FH, Schmieder RE. A metaanalysis of the effects of treatment on left ventricular mass in essential hypertension. Am J Med. 2003; 115: 41-6.

19. Yusuf S, Pfeffer MA, Swedberg K, Granger CB, Held P, MCMurray JJ, et al. Effects of candesartan in patients with chronic heart failure and preserved left-ventricular ejection fraction: the CHARM-Preserved Trial. Lancet. 2003; 362: 777-81.

20. The effect of digoxin on mortality and morbidity in patients with heart failure. The Digitals Investigation Group. N Engl J Med. 1997; 336: 525-33.

21. Hogg K, McMurray JJV. Neurohumoral pathways in heart failure with preserved systolic function. Prog Cardiovasc Dis. 2005; 47: 357-66.

22. Susic D, Frohlich DE. Optimal treatment of hypertension with diastolic heart failure. Heart Fail Clin. 2008; 4: 117-24.

23. Desai A, Fang JC. Heart failure with preserved ejection fraction: hypertension, diabetes, obesity/sleep apnea, and hypertrophic and infiltrative cardiomyopathy. Heart Fail Clin. 2008; 4: 87-97.

24. Hogg K, McMurray J J V. Treatment of heart failure with preserved systolic function: a review of the evidence. Eur Heart J Suppl. 2004; 6: h61-h66.

25. Setaro JF, Zaret BL, Schulman DS, Black HR, Soufer R. Usefulness of verapamil for congestive heart failure associated with abnormal left ventricular diastolic filling and normal left ventricular systolic performance. Am J Cardiol. 1990; 66: 981-6.

26. Hung MJ, Cherng WJ, Kuo LT, Wang CH. Effect of verapamil in elderly patients with left ventricular diastolic dysfunction as a cause of congestive heart failure. Int J Clin Pract. 2002; 56: 57-62.

27. Lester SJ, TajikAJ, Nishimura RA, Oh JK, Khandheria BK, Seward JB. Unlocking the mysteries of diastolic function deciphering the Rosetta stone 10 years later. J Am Coll Cardiol. 2008; 51: 679-89.

28. Aronow WS, Ahn C, Kronzon I. Effect of propranolol versus no propranolol on total mortality plus nonfatal myocardial infarction in older patients with prior myocardial infarction, congestive heart failure, and left ventricular ejection fraction $40 \%$ treated with diuretics plus angiotensin-converting-enzyme inhibitors. Am J Cardiol. 1997; 80: 207-9.

29. Dobre D, Van Veldhuisen D, deJongste M, Haaijer-Ruskamp F. Prescription of beta-blockers in patients with advanced heart failure and preserved left ventricular ejection fraction: clinical implications and survival. Eur J Heart Fail. 2007; 9: 280-6.

30. Dobre D, Van Veldhuisen D, Mordenti G, Vintila M, Haaijer-Ruskamps FM, Coats AJ, et al. Tolerability and dose-related effects of nebivolol in elderly patients with heart failure: data from the Study of the Effects of Nebivolol
Intervention on Outcomes and Rehospitalisation in Seniors with Heart Failure (SENIORS) trial. Am Heart J. 2007; 154; 109-15.

31. Bergström A, Andersson B, Edner M, Nylander E, Persson H, Dahlström $\mathrm{U}$. Effect of carvedilol on diastolic function in patients with diastolic heart failure and preserved systolic function: results of the Swedish Dopplerechocardiographic study (SWEDIC). Eur J Heart Fail. 2004; 6: 453-61.

32. Yip GWK, Wang M, Wang T, Chan S, Fung JWH, Yeung L, et al. The Hong Kong diastolic heart failure study: a randomised controlled trial of diuretics, irbesartan and ramipril on quality of life, exercise capacity, left ventricular global and regional function in heart failure with a normal ejection fraction. Heart. 2008; 94: 573-80.

33. Psaty BM, Lumley T, Furberg CD, Schllenbaum G, Pahor M, Alderman MH, et al. Health outcomes associated with various antihypertensive therapies used as first-line agents: a network meta-analysis. JAMA. 2003; 289: 2534-44.

34. Sica DA, Gehr TWB, Frishman WH. Use of diuretics in the treatment of heart failure in the elderly. Clin Geriatr Med. 2007; 23: 107-21.

35. Brilla CG, Funck RC, Rupp H. Lisinopril-mediated regression of myocardia fibrosis in patients with hypertensive heart disease. Circulation. 2000; 102 1388-93.

36. Cleland JG, Tendera M, Adamus J, Freemantle N, Polonski L, Taylor J. The Perindopril in Elderly People with Chronic Heart Failure (PEP-CHF) study. Eur Heart J. 2006; $27: 2338-45$

37. Pitt B, Reichek N, Willenbrock R, Zannad F, Phillips RA, Roniker B, et al. Effects of eplerenone, enalapril, and eplerenone/enalapril in patients with essentia hypertension and left ventricular hypertrophy. The 4E-Left Ventricular Hypertrophy Study. Circulation. 2003; 108: 1831-8.

38. McMurray JJV, Pitt B, Latini R, Maggioni AP, Solomon SD, Keefe DL, et al. Effects of the oral direct renin inhibitor aliskiren in patients with symptomatic heart failure. Circ Heart Fail. 2008; 1: 17-24.

39. Massie BM, Abdalla I. Heart failure in patients with preserved left ventricula systolic function: do digitalis glycosides have a role? Prog Cardiovasc Dis. 1998; 40: 357-69

40. Fukuta H, Sane DC, Brucks S, Little W C. Statin therapy may be associated with lower mortality in patients with diastolic heart failure: a preliminary report. Circulation. 2005; 112: 357-63.

41. Vitale C, Wajngarten M, Sposato B, Gebara O, Rossini P, Fini M, et al Trimetazidine improves left ventricular function and quality of life in elderly patients with coronary artery disease. Eur Heart J. 2004; 25: 1814-21.

42. Carson P, Massie B M, McKelvie R, McMurray J, Komajda M, Zile M, et al. The irbesartan in heart failure with preserved systolic function (I-PRESERVE) trial: rationale and design. J Card Fail. 2005; 11 (8): 576-85.

43. Little WC, Zile MR, Kitzman DW, Hundley WG, O'Brien TX, Degroof RC. The effect of alagebrium chloride (ALT-711), a novel glucose cross-link breaker, in the treatment of elderly patients with diastolic heart failure. J Card Fail. 2005; 11: 191-5.

44. Steg P G. Overview of large morbidity/mortality trials with ivabradine: focus on the BEAUTIFUL study. Eur Heart J Suppl. 2007; 9: F15-F19.

45. Danchin N. If current inhibition with ivabradine: further perspectives. Eur Heart J Suppl. 2003; 5: G52-G56.

46. Zile MR, Brutsaert DL. New concepts in diastolic dysfunction and diastolic heart failure: Part II: causal mechanisms and treatment. Circulation. 2002; 105: 1503-8.

47. Anand I, McMurray JJV, Cohn JN, Konstam MA, Notter T, Quitzau K. Longterm effects of darusentan on left-ventricular remodelling and clinical outcomes in the Endothelin A Receptor Antagonist Trial in Heart Failure (EARTH): randomised, double-blind, placebo-controlled trial. Lancet. 2004 364: 347-54.

48. Waggoner A D, Faddis M N, Gleva M J, de las Fuentes, L, D'Avila-Román VG. Improvements in left ventricular diastolic function after cardiac resynchronization therapy are coupled to response in systolic performance. J Am Coll Cardiol. 2005; 46: 2244-9. 